\title{
A single base mutation in COL5A2 causes Ehlers-Danlos syndrome type II
}

\author{
Allan J Richards, Sam Martin, Alan C Nicholls, J Barrie Harrison, F Michael Pope, \\ Nigel P Burrows
}

\section{MRC Connective Tissue Genetics Group, Department of Pathology, University of Cambridge, Tennis Court Road, Cambridge CB2 1QP, UK \\ A J Richards \\ $S$ Martin \\ A C Nicholls \\ J B Harrison \\ F M Pope \\ N P Burrows}

\section{MRC Connective \\ Tissue Genetics \\ Group, Institute of \\ Medical Genetics, \\ University Hospital of \\ Wales, Heath Park, \\ Cardiff CF4 4XN, UK \\ F M Pope}

\section{Department of}

Dermatology,

Addenbrooke's NHS

Trust, Hills Road,

Cambridge CB2 2QQ,

UK

N P Burrows

Correspondence to:

Dr Burrows.

Received 15 December 1997 Revised version accepted for publication 6 March 1998

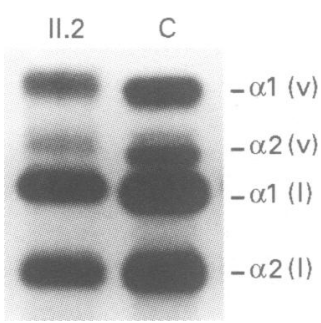

Figure 1 Protein analysis. Radiolabelled proteins secreted from cultured dermal fibroblasts from an affected family member (II.2) and a control (C) were treated with pepsin and subjected to $S D S-P A G E$ and fluorography. The a chains of types $I$ and $V$ collagen were visible as indicated.

\begin{abstract}
Ehlers-Danlos syndrome (EDS) is a heterogeneous group of connective tissue disorders. Recently mutations have been found in the genes for type $V$ collagen in a small number of people with the most common forms of EDS, types I and II. Here we characterise a COL5A2 mutation in an EDS II family. Cultured dermal fibroblasts obtained from an affected subject synthesised abnormal type $V$ collagen. Haplotype analysis excluded COL5A1 but was concordant with COL5A2 as the disease locus. The entire open reading frame of the COL5A2 cDNA was directly sequenced and a single base mutation detected. It substituted a glycine residue within the triple helical domain (G934R) of $\alpha 2(V)$ collagen, typical of the dominant negative changes in other collagens, which cause various other inherited connective tissue disorders. All three affected family members possessed the single base change, which was absent in 50 normal chromosomes.
\end{abstract}

( $($ Med Genet 1998;35:846-848)

Keywords: COL5A2; mutation; Ehlers-Danlos syndrome

Mutations in the genes for type $\mathrm{V}$ collagen (COL5A1 and COL5A2) have recently been reported $^{1.4}$ in cases of the commonest forms of Ehlers-Danlos syndrome (EDS types I and II). Other EDS types also have defects which result in abnormal collagen molecules. Fibrillar collagens are the most abundant extracellular matrix components and fibrils may be heterotypic, being composed of more than one collagen type. ${ }^{56}$ The fibrillar collagen family includes the highly homologous types I, II, III, $\mathrm{V}$, and XI proteins, each with a long uninterrupted triple helix of Gly-X-Y repeats. ${ }^{7} \mathrm{Al}-$ though type $\mathrm{V}$ and $\mathrm{XI}$ collagens are quantitatively minor fibrillar components, they have an important role in regulating the assembly and structure of the more abundant fibril forming collagens (types I, II, and III), with which they are coexpressed. ${ }^{89}$ Type $\mathrm{V}$ collagen is more abundant in tissues expressing types I and III collagen, and usually exists as an $[\alpha 1(\mathrm{~V})]_{2} \alpha 2(\mathrm{~V})$ heterotrimer, ${ }^{10-12}$ which is the product of the COL5A1 and COL5A2 genes. There is evidence that the diameter of fibrils composed of either type I or type II collagen is regulated by the relative proportion of type $\mathrm{V}$ or XI collagen respectively. Experiments which artificially altered the ratio of type $\mathrm{V}$ or XI col- lagen to the more abundant collagen typs resulted in altered fibril diameters. ${ }^{13-15}$ Al corneal collagen fibrils, where type V collagö represents a much larger proportion (15-20\%) of the total fibrillar collagen, ${ }^{16}{ }^{17}$ are smaller than in other type I collagen expressing tissues, where type $V$ collagen is less abundant $\left(2-5^{\circ}\right.$,

Not all EDS I/II pedigrees are linked đo COL5A1 or COL5A2 ${ }^{18}$ (N P Burrows, unpuge lished results) and other candidate geries include those for decorin ${ }^{19}$ and tenascin $X_{\infty}^{20}$ While it is preferable initially to perfo haplotype analysis in multigeneration families, for sporadic cases or small families it is often unhelpful. Here we describe a COL5A2 muQtion in a small family which showed the clinifal phenotype of EDS II (NPB). Electron mict scopic analysis of dermal collagen structure in this family showed only minor variability in the collagen fibril size and shape (data not shown). Cultured skin fibroblasts were labelled with proline and the collagens synthesised werfe analysed by SDS polyacrylamide gel electiphoresis (fig 1). Type V collagen from the coll line migrated more slowly than that from $\mathrm{a}_{a}$ control. Similar observations have been mad̄e in cases of osteogenesis imperfecta where mutations in either COL1A1 or COL1 cause overmodification of both $\alpha 1(\mathrm{I})$ and $\alpha 2(\mathrm{I})$ collagen proteins. ${ }^{21}$ Thus, in this case it w⿳亠口冋口灬

COL5A1 $1 \frac{0}{10}$ D9S1818 1 这

COL3A1 2 蛋 D2S389 3 俥

। III
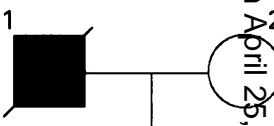

II

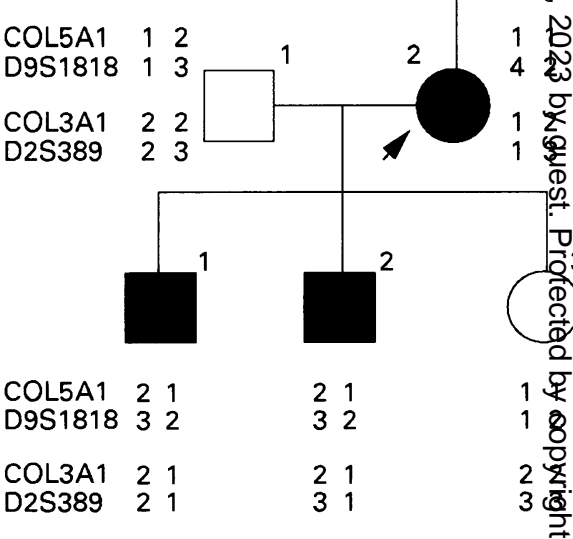

Figure 2 Haplotype analysis. DNA from available family members was amplified using oligonucleotides for various markers as indicated. After separation on a polyacrylamide gel and autoradiography, the haplotype of each subject was scored and is noted on the family pedigree. The arrowhead denotes the proband. 


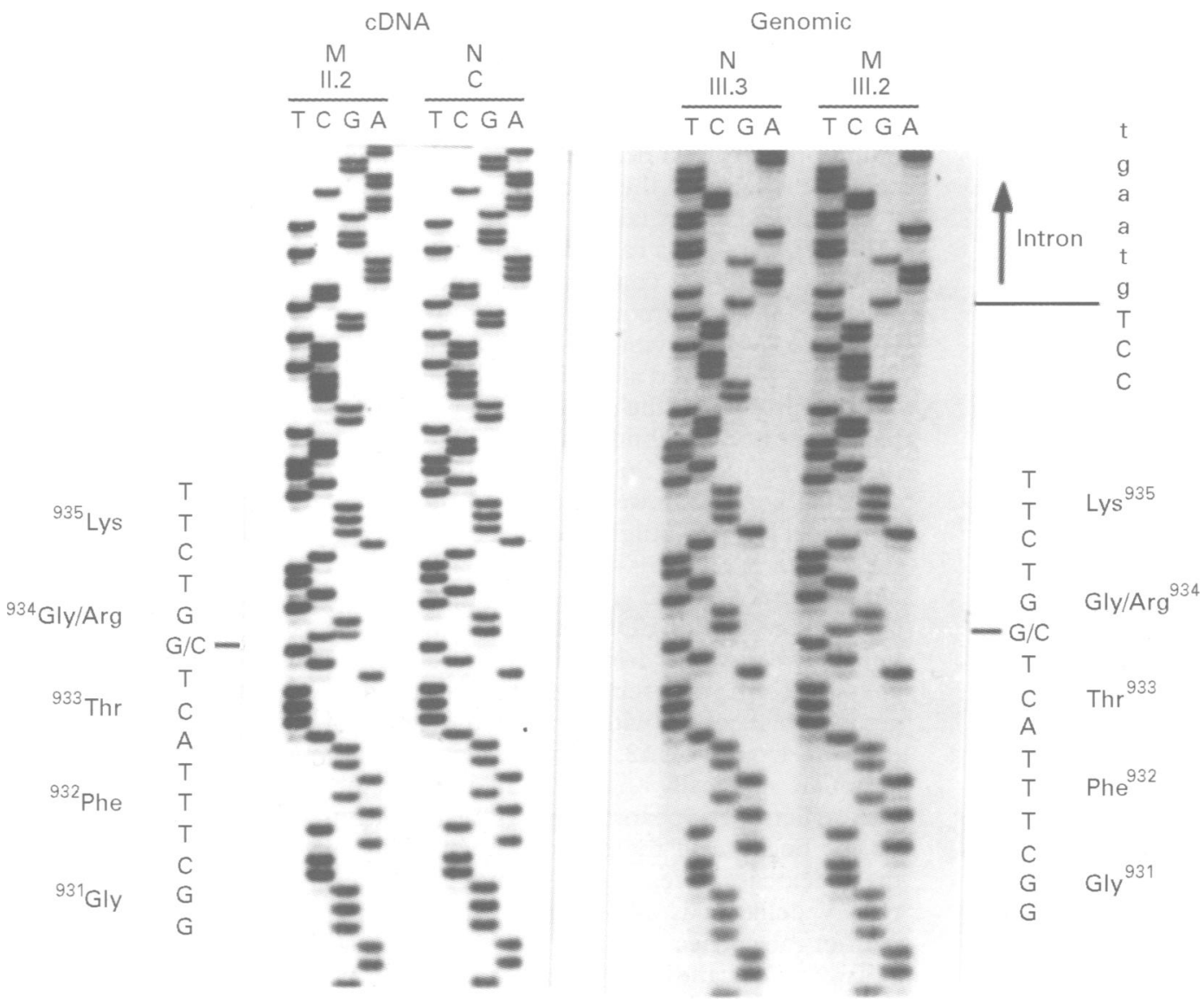

Figure 3 Sequence analysis. The mutant (M) and normal (N) cDNA and genomic sequence obtained from various family members or control (as indicated) is shown. The same sense primer was used for each sequencing reaction. The DNA and corresponding amino acid sequences are written adjacent to the autoradiographs. The heterozygous $G / C$ base change which converts glycine 934 to arginine is indicated, as is the position of the intron within the genomic sequence.

likely that there was a mutation in either COL5A1 or COL5A2.

Haplotype analysis was undertaken using markers (COL5A1, D9S1818, COL3A1, and D2S389) within or close to either COL5A1 or COL5A2. ${ }^{18225}$ The haplotypes (fig 2) excluded COL5A1, but were concordant with COL5A2 as the disease locus. While the family was too small to generate a significant lod score, the combination of protein profile with haplotype analysis strongly implied a causative mutation in COL5A2. The CDNA for the complete coding sequence of $\alpha 2(\mathrm{~V})$ collagen (accession NoY14690) was reverse transcribed and amplified from RNA as 11 overlapping products. Each of these were directly sequenced. A single base mutation was seen, which converted an obligatory glycine within the triple helical region of the molecule to arginine (fig 3). This change was confirmed in each affected family member by amplification and sequencing (fig 3) of a 500 bp genomic DNA product. Each affected subject contained the same $G$ to $C$ base change (data are only shown for III.2), and an intron was positioned between bases 3600 and 3601 of the cDNA sequence (fig 3). The mutation abolished a $B s r I$ restriction enzyme site which normally removed $80 \mathrm{bp}$ from one end of the $500 \mathrm{bp}$ product. Incubation of the amplified genomic DNA with this enzyme confirmed the sequencing results (fig 4) and that this change was absent in 50 chromosomes from 25 unrelated controls.

This alteration is typical of many mutations in other fibrillar collagens which cause inherited disorders, such as osteogenesis imperfecta, the chondrodysplasias, and EDS type $\mathrm{IV}^{26}$ This, along with the absence of this change in normal subjects, provides strong evidence that it is the causative mutation in this EDS II family. Only a few mutations of COL5A1 and

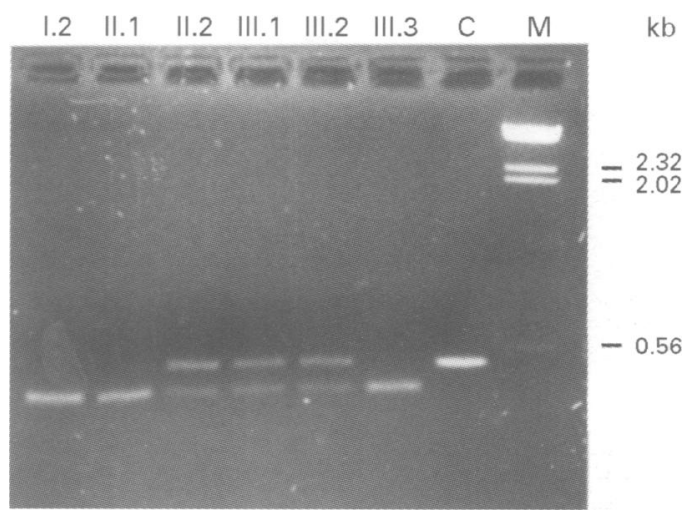

Figure 4 Restriction enzyme digestion. Genomic DNA from each family member (as indicated) was amplified and incubated with the restriction enzyme BsrI. Electrophoresis on a $2 \%$ agarose gel was used to separate the products, along with undigested DNA $(C)$ and DNA of known sizes used as markers (M). 
COL5A2 have been characterised in EDS I/II patients. $^{1-4}$ Three of these affect the C-propeptide and possibly inhibit assembly of the mutant collagen with normal $\alpha$ chains. Others affect the correct splicing of exons coding for part of the triple helix. These, like the mutation described here, will have a dominant negative effect, as they will coassemble with normal collagen $\alpha$ chains.

COL5A2 is also a candidate for Stickler syndrome as $\alpha 2(\mathrm{~V})$ coassembles with $\alpha 1(\mathrm{XI})$ collagen in the vitreous ${ }^{27}$ and a mutation in COL11A1 was previously shown to cause that disorder. ${ }^{28}$ However, a detailed ophthalmological examination of the proband from this EDS family showed no abnormality of the vitreous, thereby excluding Stickler syndrome. However, the cornea showed keratoconus, a developmental forward bulging of the central area of the cornea. A previous study of 44 patients with keratoconus showed that $50 \%$ had clinical signs suggestive of EDS, indicating a possible link between these disorders. ${ }^{29}$ These corneal changes confirm observations seen in a transgenic mouse model with a targeted deletion of exon 6 from col5 $22 .^{30}$ Heterozygous mice, although clinically normal, had abnormal ultrastructural appearance of corneal collagen fibrils. Because of the corneal abnormality of the index case here, it is likely that in humans type $\mathrm{V}$ collagen is also an important component of the cornea.

Two other candidate genes for EDS I/II are those which code for decorin ${ }^{19}$ and tenascin $\mathrm{X}^{20}$ In sporadic cases of EDS I/II, or small families in which exclusion of candidate genes is not possible, variation in clinical signs may provide important clues for determining which gene is mutated. In this instance the index case presented with keratoconus. Unfortunately, as the other two affected subjects were not available for ophthalmic examination, we do not know if it segregates with EDS in this family. However, there has been one previous report of flattened corneas associated with a COL5A1 mutation. ${ }^{2}$ It is possible, therefore, that abnormal corneal morphology may indicate the presence of COL5A1 and COL5A2 mutations in other EDS patients.

We would like to thank Mr M P Snead for ophthalmic examination of the proband and Mrs M Laidlaw for assistance with tissue culture. NPB was supported by a grant from the Wellcome Trust (044116)

1 Wenstrup RJ, Langland GT, Willing MC, Dsouza VN, Cole WG. A splice-junction mutation in the region of COL5A1 that codes for the carboxyl propeptide of pro- $\alpha 1(\mathrm{~V})$ chains results in the gravis form of Ehlers-Danlos syndrome (type I). Hum Mol Genet 1996;5:1733-6.

2 Nicholls AC, Oliver JE, McCarron S, Harrison JB, Greenspan DS, Pope FM. An exon skipping mutation of a type $\mathrm{V}$ collagen gene (COL5A1) in Ehlers-Danlos syndrome. F Med Genet 1996;33:940-6.

3 De Paepe A, Nuytink L, Hausser I, Anton-Lamprecht I, Naeyaert JM. Mutations in the COL5A1 gene are causal in the Ehlers-Danlos syndromes I and II. Am $\mathcal{F}$ Hum Genet 1997;60:547-54.
4 Michalickova K, Susic M, Willing MC, Wenstrup RJ, Cole WG. Mutations of the $\alpha 2(\mathrm{~V})$ chain of type $\mathrm{V}$ collagen impair matrix assembly and produces Ehlers-Danlos syndrome type I. Hum Mol Genet 1998;7:249-55.

5 Mendler M, Eich-Bender SG, Vaughan L, Winterhalfer $\mathrm{KH}$, Bruckner P. Cartilage contains mixed fibrils 정 collagen types II, IX and XI. $\mathcal{F}$ Cell Biol 1989;108:191-7.

6 Birk DE, Fitch JM, Babiaz JP, Doane KJ, Linsenmayer TP Collagen fibrillogenesis in vitro: interaction of types I and. collagen regulates fibril diameter. $\mathcal{F}$ Cell Sci 1990;95:64 57.

7 Van Der Rest M, Garrone R. The collagen family of proteins. FASEB f 1991;5:2814-23.

8 Linsenmayer TF, Gibney E, Igoe F, et al. Type V collagêt. molecular structure and fibrillar organization of chick al(V) NH2-terminal domain, a putative regulator corneal fibrillogenesis. $\mathcal{F}$ Cell Biol 1993;121:1181-9.

9 Fichard A, Kleman JP, Ruggiero F. Another look at collage $\mathrm{V}$ and XI molecules. Matrix Biol 1995;14:515-31.

10 Burgeson RE, El Adli FA, Kaitila II, Hollister DW. Fe@ి membrane collagens: identification of two new collagenge chains. Proc Natl Acad Sci USA 1976;73:2579-83.

11 Elstow SF, Weiss JB. Extraction, isolation and characteriz $\overrightarrow{2-}$ tion of neutral salt soluble type $\mathrm{V}$ collagen from fetal calf skin. Collagen Rel Res 1983;3:181-94.

12 Broek DL, Madri J, Eikenberry EF, Brodsky B. Charactefi zation of the tissue form of type $\mathrm{V}$ collagen from chig bone. F Biol Chem 1991;260:555-62.

13 Marchant JK, Hahn RA, Linsenmayer TF, Birk DE. Reduc tion of type $\mathrm{V}$ collagen using a dominant-negative strategy alters the regulation of fibrillogenesis and results in the loss of corneal-specific fibril morphology. $F$ Cell Biol 1996;13 1415-26.

14 Li Y, Lacerada DA, Warman ML, et al. A fibrillar collage gene, COL11A1, is essential for skeletal morphogenesios Cell 1995;80:423-30.

15 Garofalo S, Metsaranta M, Ellard J, et al. Assembly of car lage collagen fibrils is disrupted by overexpression of normal type II collagen in transgenic mice. Proc Natl Acda Sci USA 1993;90:3825-9.

16 Tseng SCG, Smuckler D, Stern R. Comparison of collag types in adult and fetal bovine corneas. F Biol Chem 198
257:2627-33.

17 McLaughlin JS, Linsenmayer TF, Birk DE. Type V collagen synthesis and deposition by chicken embryo corneal fibreo blasts in vitro. $¥$ Cell Sci 1989;94:371-9.

18 Greenspan DS, Northrup H, Au KS, et al. COL5A1: fine genetic mapping and exclusion as candidate gene families with nail-patella syndrome, tuberose sclerosis hereditary hemorrhagic telangiectasia and Ehlers-Danlos syndrome type II. Genomics 1995;25:737-9.

19 Danielson KG, Baribault H, Holmes DF, Graham I9 Kadler KE, Iozzo RV. Targeted disruption of decorin leađs to abnormal collagen fibril morphology and skin fragility. $\mathcal{F}$ Cell Biol 1997;136:729-43.

20 Burch GH, Gong Y, Liu W, et al. Tenascin-X deficiency 8 associated with Ehlers-Danlos syndrome. Nat Genet 1997, 17:104-8

21 Bonadio J, Byers PH. Subtle structural alterations in the chains of type I procollagen produce osteogenesis imper: fecta type II. Nature 1985;316:363-6.

22 Lee B, Vitale E, Superti-Furga A, Steinmann B, Ramirez $\vec{B}$ $G$ to $T$ transversion at position +5 of a splice donor site causes skipping of the preceding exon in the type If procollagen transcripts of a patient with Ehlers-Danlys. syndrome type IV. $\mathcal{F}$ Biol Chem 1991;266:5256-9.

23 Cutting GR, McGinniss MJ, Kasch LM, Tsipouras $P$ Antonarakis SE. Physical mapping by PFGE localizes the COL $3 A 1$ and COL5A2 genes to a $35-k b$ region on humag chromosome 2. Genomics 1990;8:407-10.

24 Dib C, Faure S, Fizames C, et al. A comprehensive genetie map of the human genome based on 5,264 microsatellite Nature 1996;380:152-4.

25 Schuler GD, Boguski MS, Stewart EA, et al. A gene map off the human genome. Science 1996;274:540-6.

26 Kuivaniemi H, Tromp G, Prockop DJ. Mutations in fibrillar collagens (type I, II, III and XI, fibril-associated collage? (type IX), and network-forming collagen (type X) cause (2) spectrum of diseases of bone, cartilage and blood vesselo Hum Mutat 1997;9:300-15.

27 Mayne R, Brewton RG, Mayne PM, Baker JR. Isolation anf characterization of the chains of type V/type XI collage characterization of the chains of type V/type XI collage
present in bovine vitreous. $₹$ Biol Chem 1993;268:9381-6.

28 Richards AJ, Yates JRW, Williams R, et al. A family with Stickler syndrome type 2 has a mutation in the COL11A gene resulting in the substitution of glycine 97 by valine a1(XI) collagen. Hum Mol Genet 1996;5:1339-43.

29 Robertson I. Keratoconus and the Ehlers-Danlos syndrom? a new aspect of keratoconus. Med f Aust 1975;1:571-3. (D)

30 Andrikopoulos $\mathrm{K}, \mathrm{Liu} X$, Keene DR, Jaenisch R, Ramirez Targeted mutation in the col5a 2 gene reveals a regulato Targeted mutation in the col5a2 gene reveals a regulato role for type 